\title{
Emergence of Differential Social License: A Case of Impact and Benefit Agreements in Nunavut, Canada
}

\author{
Michael Hitch ${ }^{1 *}$, Michael Tost ${ }^{2}$, Susanne Feiel ${ }^{2}$ and Peter Moser $^{2}$ \\ ${ }^{1}$ Australian Centre for Sustainable Mining Practices, UNSW Sydney, Sydney Australia \\ ${ }^{2}$ Department of Mining Engineering and Mineral Economics, Montanuniversitaet Leoben, Austria
}

\begin{abstract}
Impact and Benefit Agreements (IBAs) are intended to be a negotiated agreement between an industrial proponent and a community, local or regional citizens' organization. Although the elements have grown over the past two decades from a simple agreement to exceedingly complex legal frameworks, the intention remains the same: to outline the roles and responsibilities of the two stakeholders and the natural resource development on their lands beyond environmental assessment. These agreements were born out of comprehensive indigenous land claims and have become the cornerstone of community engagement today in most indigenous nations. In the case of mixed communities, those that have beneficiaries of land claims and those who are not, social acceptance remains uneven and reflective of an unequal distribution of decisionmaking power (political ecology). This Differential Social License can cause conflict and a breakdown of the societal fabric that binds communities of diverse populations, resulting in inequality, fictitious wealth generation and failure of infrastructure.

This paper presents a case study of how the development of Differential Social License developed in the Hamlet of Cambridge Bay, Nunavut as a result of an IBA negotiated between Tahera Diamond Corp. and the Kitikmeot Inuit Organisation in 2004 for the Jericho Diamond Mine.
\end{abstract}

Keywords: impact and benefit agreements, arctic social license, Nunavut natural resource development

\section{Introduction / Background}

Social license (social license to operate or SLO) has become an essential part of the social governance 'toolkit' demanded by mining stakeholders in today's world. Stakeholders are now insistent that companies operate more closely under the tenets of sustainable development and provide for an increased level of community participation.

Social license is not simply a matter of communicating with a community, to earn its consent for or acceptance of a project. It requires that we engage with the individuals and organisations who ally themselves with communities, or who sometimes side with dissident factions of a community. SLO is a process associated with and informed by political ecology or the recognition that unequal decision-making power exists amongst stakeholders.

Impact and benefit agreements (IBAs) represent one approach to approximating social license in the mineral sector. They are a mechanism for promoting resource development in a manner that contributes to the sustainability of the local environment and economy, and the social and cultural fabric of affected communities (Keith 1995, O'Reilly 1999, O'Reilly and Eacott 1998). IBAs became a significant component of settled aboriginal land claim treaties globally and include some well-known decisions including Mabo Judgment in Australia (Reynolds
1993, O'Faircheallaigh 1999) and the Gwich'in and Sahtu in Canada (Keeping 1999).

Today, IBAs are negotiated with representative organisations (comprised of almost exclusively First Nations or Indigenous people) and encompass a variety of arrangements and instruments of agreement. They generally provide opportunities for communities to derive economic benefits from natural resource development projects that affect them, and to participate in the management, monitoring and mitigation of social, cultural, economic and environmental impacts.

By their very nature, IBAs are negotiated by a representative body who are entrusted with safeguarding the interests of the community. In some cases, a community is not homogeneous (i.e. Non-First Nations/Indigenous) as is the case in Cambridge Bay in Nunavut. The Hamlet of Cambridge Bay is administered by the Nunavut territorial government where the population is $85 \%$ aboriginal and the remaining of other origin (StatsCan 2016). Of the group that report as aboriginal, approximately $79 \%$ identify as Inuvutmiut and therefore are legal beneficiaries of the Nunavut Comprehensive Land Claims Agreement (NCLA) and therefore any IBA negotiated on their territorial lands. The remaining portion of the community depends on small businesses and the Canadian Federal Government services for their economic livelihood. This apparent dichotomy pits

* Corresponding Author: M. Hitch, m.hitch@unsw.edu.au, phone: +61 2-93857946

Copyright @ 2017 Canamaple Academia Services, http://press.camdemia.ca

DOI: $10.15273 /$ gree.2017.02.044 
the interest of one group against another, particularly when the prospect of high paying jobs and business opportunities associated with mineral development are at stake.

This paper reflects on research looking at the contribution of mineral directed IBAs in a mixed community in Arctic Canada as illustrated in a case study of Tahera Diamonds Ltd.'s Jericho mine development and their negotiated impact and benefit agreement with the Kitikmeot Inuit Association in 2004. What makes this review unique is the mixed nature of the community and the realisation that the juxtaposition of power relationships and occurrence of 'differential' social licence amongst actors.

\section{Theoretical Framework: Political Ecology}

Political ecology is a historical outgrowth of many of the central questions posed by social scientists about the relations between human societies in the context of their bio-cultural-political complexity (Gouldson and Murphy 1997). In particular, it addresses the unequal distribution of decision making power amongst affected actors in a natural resource development scenario. Political ecology, furthermore, draws on a number of theoretical perspectives including dependency theory, political economy and systems thinking.

Another way of looking at political ecology is to see it as rejecting the view that environmental degradation can be understood as a simple problem amenable to a scientific fix or response. Instead political ecology stresses there is an ecology of politics and a politics of ecology. Wolford (2005) proposed that there is a central role in that distribution, allocation and extraction of natural resources that shapes the nature of social institutions within society.

Today, mineral development initiatives bring a varied cast of actors to the stage, such as NGOs and members of First Nations or Indigenous Peoples groups. These actors are predominantly interested in ensuring that the resources are developed and extracted with minimum impact on the biophysical and social aspects of their environment, while at the same time providing an equitable distribution of the revenues (Fidler and Hitch 2008).

In this study, the authors used Political Ecology as a theoretical framework or philosophical lens through which to observe how the community dynamic evolved particularly given its mixed (Inuit/non Inuit) composition.

\section{Method}

The results presented in this paper reflect observations from a much larger analysis of Impact Benefit Agreements and their effectiveness in supporting sustainable development in Nunavut. That work (Hitch 2006, Fidler and Hitch 2008) developed and verified a sustainable mining criteria against four similar agreements (i.e. Diavik, Voisey's Bay, Ulu, Raglan and Donna Lake. Based on that reconciliation, the criterial was validated and applied to the Jericho IBC, that was being concluded at that time. Key informant interviews and discourse analysis were used to substantiate and add colour' to an in-depth literature review.

\section{Jericho Diamond Mine}

In September, 2004 Tahera Diamonds and the Kitikmeot Inuit Organisation (KIA) signed what was then considered a "state of the art' IBA in terms of its ability to satisfy many elements associated with sustainable development. Tahera planned to construct and operate the Jericho Mine near the north end of Contwoyto Lake in West Kitikmeot, Nunavut. At the time, Tahera was a Canadian exploration company engaged in the exploration and development of diamond deposits in Nunavut and the Northwest Territories in Canada's north. It no longer exists today.

The Jericho project, located approximately $400 \mathrm{~km}$ northeast of Yellowknife NWT, consisted of two separate kimberlite clusters. Operations were to consist initially of an open pit followed by underground mining. Mining would take place over eight months of the year and goods and supplies would be transported over ice roads. The mine plan provided for an eight-year mine life and total employment was expected to be 105 to 175 people (including employees and contractors) with a priority given to signatories of the Nunavut Comprehensive Land Claims Agreement (Inuvutmiut peoples), who were primarily located in nearby hamlet of Cambridge Bay.

The extent of the effectiveness of sustainability efforts and how they contribute to the goal of achieving social licence is highly dependent on how the stakeholders accept, relinquish and share the decision making power associated with development. The following section examines some characteristics of sustainable mining practices in terms of their political ecology.

\section{Sustainability Criteria and the Jericho IBA}

Hitch (2010) developed criteria of sustainability for development on First Nations/Indigenous lands and was used to evaluate six precedent IBAs. These criteria also formed the cornerstone aspects of the Tahera/Jericho IBA model. It is interesting to note that these criteria also reflect those characteristics we expect from a holistic SLO lens one would consider today. These criteria included:

- Holistic Company Policies - indicative of a company's recognition of more than economic performance but inclusive of the environment and all its components;

- Aboriginal Partnerships and Coordination - giving communities and their agents access to forums of decision making through inclusion;

- Training and Education - allows the affected community to develop its own skills sets and tools to pursue a future beyond the live of the mine;

- Employee Participation and Community Well Being recognises the community's cultural needs as well as appropriate labour relations;

- Community Capacity Building - organic development of self-determination and power through self-directed capacity building and enhancement; and

- Community Participation and Information Disclosure - the opportunity for the community to voice opinion and provide input. 


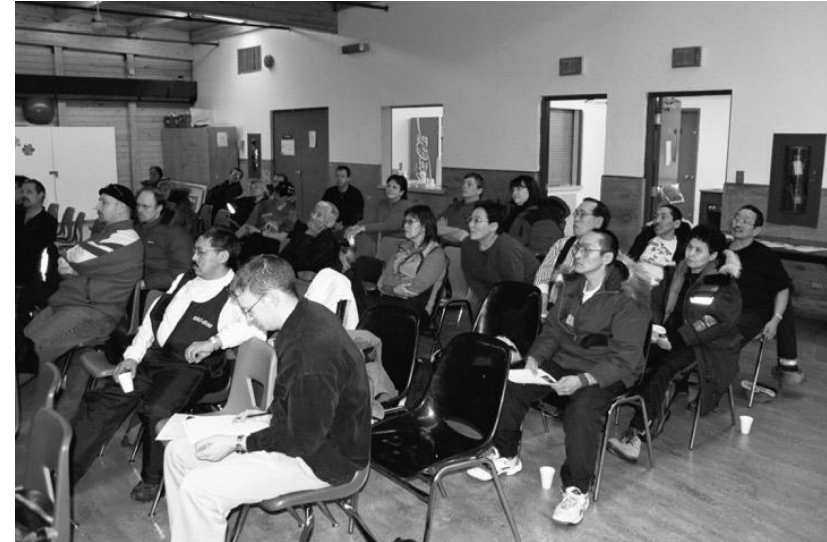

Figure 1. Tahera Diamonds public consultation meeting, Cambridge Bay NT (11/09/2004).

\section{Where the Jericho IBA Succeeded and Where it Fell Short}

Although, as stated earlier, the Jericho agreement was considered a shining example of modern day IBAs and furthermore reflected the essential core themes and elements of sustainable mining practices, it was revealed that there were 'cracks in the scenery' in terms of complete social license. The following sections look at these core sustainability themes and presents comments from local population.

\section{Holistic Company Policies}

These elements require a commitment by the company to act in a responsible manner to instill trust with the affected community. To illustrate the importance of this, while one community respondent strongly supported Southern companies coming into the community, he also emphasized the need to work with the Inuvutmiut beyond the token level. He commented:

"I've seen too many potato companies that have nothing at stake. One or two Inuit will benefit from the booze and the drugs and the free flowing money. However, with real Inuit companies, we insist on training for Inuit and employment."

One community member believed Southern companies fail to get to know the local community, particularly the elders. This respondent thinks Southern company staff should spend more time in the community and become active participants. She commented:

"Sometimes I wish they got to know the people first and to understand what it is like up here and see how much we rely on our land for food."

${ }^{1}$ A potato company is a slang term for a company that appears to be Inuvutmiut. However, it is largely managed behind the scenes by non-Inuits.
Tahera spent over four years conducting public meetings and consultations. One industry representative attributed much of the success in negotiating the Jericho IBA to the continuous and careful explanation of the project by Tahera.

\section{Aboriginal Partnerships and Cooperation}

Mineral development brings change to traditional ways of life. The challenges of bringing about positive changes and minimizing the negative influences motivate Aboriginal communities to pursue partnerships with the industrial proponent. This criterion centers on the company's support of initiatives to enhance Aboriginal involvement in mineral and metal activities, including examining potential incentives for the company to work with the Aboriginal community, promoting joint ventures between Aboriginal businesses and non-Aboriginal mineral developments, and improving Aboriginal access to capital.

While jobs and wealth creation could be the underpinnings of prosperous, self-reliant communities, many Aboriginal communities have limited economic opportunity and capacity, and have difficulty accessing the tools they need in order to build economic self-reliance. There has been a lack of diverse economic and business opportunities available to Aboriginal people, businesses and communities. Most Aboriginal businesses are small serving local and regional markets, and have difficulty accessing broader markets. Minerals, metals and related sector activities have the potential to provide royalties, direct and indirect income, business partnerships and spinoff opportunities for local and regional businesses.

A KIA representative sees joint ventures and the establishment of new companies as a key element of a sustainable future for the residents of Kitikmeot. The same person commented, "the possibilities are endless with a reasonable, self-derived income and any excess would go towards developing small, Inuit-owned businesses". This criterion is similar in many ways to a commitment to capacity building and enhancement discussed below.

Tahera's IBA includes several provisions for the development and support of locally-owned and operated business, including extended time frames for local businesses to prepare and negotiate contracts, extended time to prepare bid bonds, and a will to evaluate all proposals, tenders etc. on the basis of Inuit content.

\section{Training and Education}

It has been recognized by Aboriginal people and industry that a lack of necessary training and formal education is a major barrier to increasing Aboriginal participation in mining.

Recent IBAs provide for comprehensive education and training opportunities to attract qualified employees. Under these agreements, Aboriginal communities have secured benefits such as employment, education and training, which provide valuable skills that can be transferred to other mining companies and economic sectors. This facet of the IBA was the highest priority at 
the KIA and in the community at large. A KIA representative's vision for the community includes higher levels of education, employment beyond just mining, and a mobile population. This respondent saw education as the key to a sustainable future for his community. The KIA representative also saw immediate benefits arising from training. He commented:

"We are seeing more people going into post secondary education, staying through high school and this has stimulated interest in areas like geology".

A community member, who was well informed about the needs and interests of the youth of the community, recognized that a new mining operation would allow for further education and training in mining-related skills, although she saw little benefit for herself.

Not all community responses were positive. One community representative acknowledged that training and education are critical to the development and future of the community. However, he would have liked to see the Southern companies limit the number of Southern-based employees brought to the North. Another issue for this respondent was that mining companies tend to hire all of the qualified people in the community first rather than training new people from the onset. This leaves the community short of qualified employees and the community suffers. One solution this respondent suggested was to develop a jobsharing program, in which the employee will work on the mining project for two weeks at a higher wage and for two weeks for the Hamlet at the customary lower wage.

These kinds of creative approaches are required when, for example, an IBA calls for 60 employees from a community with a population of 1,600: half of the population is under working age. This leaves a very small pool that can actually fill those positions

A community member's view of the community postmining situation is bleak. This respondent saw the end of a mine's life as leaving a large part of the community without jobs, and without the ability to take back the jobs they had before, leading to situations of high depression and potentially other negative impacts. "We need to prevent that from happening", a community member commented. He felt that the best way to prevent these kinds of impacts is through cross training of people. One example he cited related to drill assistants. With drill assistants, the main task they perform is to manage drill pipe. He believed there were no transferable skills. He believed that the community as a whole needed to be training, or cross-training, these people in other positions. He believed this was the benefit of job-sharing techniques.

Tahera's IBA included many provisions for the training and education of potential employees of the mine. These concessions included assisting public educational institutions in providing training opportunities aimed at maximizing Inuit employment. These included covering the cost of these programs, developing an apprenticeship and supervisor training program, and sponsorship of preemployment training in order to increase qualifications for those Inuit who are interested in positions and training offered at Jericho. The education commitment of Tahera extended to providing upgrading programs to those Inuit wishing to upgrade their educational levels.

\section{Employee and Community Well Being}

It is well recognized that the introduction of a new mine development and a transition to a wage economy has benefits, but there also are negative impacts.

The KIA is entirely focused on the economic development of the Kitikmeot region in any way it can. As discussed earlier, the region is endowed with tremendous mineral wealth and therefore there is a natural attraction to mineral development. However, the transition to a wage economy and Southern employment structures may run contrary to traditional family culture.

A community member commented "there are office buildings in Toronto with more people in them than the entire population of the Kitikmeot". He felt that Southern companies needed to understand the sorts of challenges that Northern communities face. A conclusion is that current business models often are not applicable in the North, and sometimes unusual structures are required. Another example of the flexibility this person suggested relates to drilling companies that work on a six-week in, two-week out rotation. For the average Inuitmiut, six weeks away from home is far too long and detrimental to the family structure. If drilling operations are to hire Inuvutmiut, then companies need to adjust their shift schedules and other kinds of work commitments and conditions so that the Inuvutmiut can succeed rather than not return to work after the first rotation.

One shortcoming of current IBA structures was the perceived lack of inclusion of both the grassroots members and representatives of the local Hamlet in the negotiating process. The IBA structure and process takes place strictly between the regional Inuit association and the industrial proponent or company. The Nunavut Impact Review Board or NIRB does not have a major role to play in IBAs. Historically, part of the role of the Board is to assess how far the company has progressed since negotiations were completed with the RIA. In mid-2005, the Board wanted to impose some kind of skeletal structure to measure or at least identify the socio-economic impacts from the IBA. The goal is to provide the Board with the ability to make better decisions when assessing the appropriateness of such agreements and report back to the minister and proponent. There is no government agency or inspectors that monitor socio-economic impact. Therefore, NIRB has taken on that role in order to establish conditions and follow through with monitoring to determine how effective the IBA has been. There is a need for the RIA, the company and the board to work together in order to align interests and to develop an understanding of relative values, motives, and responsibilities, develop the contents of the IBA, and consider the direction of the agreement. When asked if the embedded feedback and monitoring mechanisms are appropriate in recent IBAs, a territorial government official responded that for the most part yes. However, in her view, the Board never sees the complete IBA document, just 
what the RIA and proponent choose to share. Historically, projects were only audited every five years and many changes to the community can occur in that time. With the IBA mechanisms, the RIA can react more quickly to negative change and install more wellness programs and educational programs to rectify problems encountered.

The same respondent's concern was that the agreements do not cover all the issues a community might face with development. In that sense, if the health and wellness programs cannot keep up with the issues that arise as a result of development, "it will not be a very happy place". Abuse will rise, along with problems regarding drugs, alcohol, health in general and all types of issues associated with rising incomes. If there is nowhere else for these trained people to utilize their new skills, things would likely become desperate for them. This same person continued, saying that "if no money is set aside to deal with these issues, that is a big problem". When asked if some provision for this kind of after-care would be appropriate for IBAs, the respondent commented:

"If I had my way an IIBA would go beyond just the Inuit Associations. It would go out and incorporate health, education and justice departments of the Government of Nunavut ("GN"). Those that are on the ground working the system, including the GN and the municipalities somehow need to be tied into the IBA. This separate agreement with the government and municipalities, is currently absent and not all of the issues that the community faces are captured by the KIA IBA."

A community member viewed the local community at risk as a result of exclusion from the IBA process. The Hamlet has no role in structuring or negotiating IBAs. It currently is pushing to be included in an 'official' capacity. Currently, IBAs are restricted to the RIAs and the RIAs do not deal with many issues that other Aboriginal bands would deal with. For example, only in Nunavut, the Hamlet is a municipal representative of the Territorial Government of Nunavut (GN) and the RIA (e.g. KIA) are representatives of the Aboriginal beneficiaries of the Nunavut Land Claims Agreement. In other Aboriginal communities, the Band is both the municipal government and the Aboriginal representative. In Nunavut, the RIAs do not administer programs such as education, health or wellness, which is not the case in Aboriginal communities outside Nunavut. The Hamlet does not receive any funding from the RIAs to provide those services to the Inuit people.

\section{Community Capacity Building and Enhancement}

One of the specified sustainability criteria used to assess the IBAs is whether they provide for the development or enhancement of community capacity and help it to move to a sustainable future beyond the life span of the mine. This criterion is related to the establishment of Aboriginal partnerships and cooperation in many respects, such as fostering secondary and tertiary business activity that can operate outside of the operations of a mine.
A KIA representative's vision for the community is to have a strong economic base with spin-off benefits such as training and education. He valued the preservation of culture and hopes over time IBAs can address social issues that come in part from overcrowding, lack of employment and things to do, and lack of motivation and goals. A strong economic base will contribute to a strong social community. This respondent saw the key to the community's success and future through economic activity:

"Up here you can't expect to generate economic activity the same way you do down South. We don't have agriculture, so a lot of what can be done down South can't be done here. We need other driving forces, such as mining, tourism, and hunting. We need to utilize existing resources whether fish or animals on the land. However, there is limited downstream processing opportunities and we need outside sources to be the driver behind economic development."

As mentioned earlier, Tahera's IBA makes provisions and sets up conditions whereby Inuit-owned and operated businesses can develop and have a distinct advantage over Southern businesses in servicing the mine's needs.

\section{Community Participation and Information Disclosure}

Community participation and the plain and full disclosure of information concerning the potential or current mineral operation are critical to have an informed and vibrant community. This goal involves community engagement and transparent corporate organization and policies. As a result of changes to Canadian securities regulations, material contracts, such as an IBA, must be filed with the relevant regulators and be considered a public document. The Jericho IBA is the first to be made public, although the company did withhold some portions regarded by it as confidential.

Prior to the conclusion of negotiations of an IBA, the corporate proponent must carry out extensive public meetings and presentations. In the case of Tahera, an industry representative and his organization had spent the previous four years visiting communities to explain not only the elements of the Jericho project but also the parent company. This respondent commented about what made the process so successful. They employed a strategy of openness, made it very clear that the company wanted to work with the communities, and made an explicit point of explaining what the opportunities might be in terms of training, employment, etc. Furthermore, the respondent made it a priority to explain to the communities what Tahera was and the responsibilities it had to its shareholders. This respondent commented that the challenge was to educate the community about the concept of profit and other market influences on a company's operations.

It became apparent through the interview process that the KIA could also strengthen its communications processes regarding the terms and conditions of IBAs and the potential benefit flow to beneficiaries. As one example, 
an industry representative mentioned that the KIA has an open-door policy and that if any beneficiary had concerns or comments they were welcome to visit and discuss them. The problem, however, is that raising concerns in this matter is considered inappropriate behavior in the local culture and it would be more likely that the issue would go unaddressed. This problem raises the issue of inclusion and assimilation of traditional knowledge and being culturally sensitive to communication strategies used in the community.

\section{The Jericho IBA and its Impact on the Community at Large}

The Tahera IBA is reflective of the thinking of the time. There was new recognition that the community was a partner in the development of the mine. There was an acknowledgment that the people and their skills were an asset and a key to the company's success. Although SLO was not part of the corporate lexicon of the time, the company approximated many of the principles.

The resulting affect, however, caused 'Differential SLO' condition to exist. As indicated earlier, an IBA is an agreement solely between two parties, the Regional Inuit organization, KIA, and the industrial proponent (Tahera) and is project specific. There is a limitation to the current thinking around IBAs and their ability to promote a sustainable future for the entire community not just the KIA community. The essential point is that not all members of the community are beneficiaries of the NCLA and therefore are not entitled to be a member of KIA and therefore benefits made available to them by the company via the IBA. The principles of sustainability, however, imply an equal opportunity to move forward together and that economic sufficiency maintenance of biophysical integrity and enhancement of social well-being are not reserved for one ethnic population but benefit everyone.

The principles of sustainability, however, imply an equal opportunity to move forward together and that economic sufficiency, maintenance of biophysical integrity and enhancement of social well-being are not reserved for one ethnic population, but benefit everyone. Several of the respondents interviewed emphasized this point, particularly relating to the Hamlet's infrastructure and its ability to manage the societal issues associated with mineral development.
In summary, the distribution of decision-making power lies largely in the hands of the KIA and to a lesser extent, with the industrial actor, with little or no power in the hands of the local community at large, resulting in goals of a sustainable mining community remaining unmet.

\section{References}

Bryant, R.L. and S. Bailey, 1997. Third world political ecology. Geographical Review, 89(1): 151.

Fidler, C. and M. Hitch, 2008. Impact and benefit agreements: A contentious issue for environmental and aboriginal justice. University of Waterloo Press Environments Journal, 35(2): 45 - 27.

Gouldson, A. and J. Murphy, 1997. Regulatory Realities: The Implementation and Impact of Industrial Environmental Policy. Earthscan, London.

Hitch, M., 2010. Impact and benefit agreements: The political ecology of mineral development in Nunavut. Verlag, Mauritius.

Keeping, J., 1999 The legal and constitutional basis for benefits agreements: a summary. Canadian Arctic Resources Committee, Northern Perspectives. http://carc.org/pubs/v25no4/3.htm.

Keith, R.F., 1995 Aboriginal communities and mining in northern Canada. Canadian Arctic Resources Committee, Northern Perspectives. http: www.carc.org/pubs/v23no3-4/mining2.htm.

O'Faircheallaigh, C., 1999. An australian perspective on impact and benefit agreements. Canadian Arctic Resources Committee, Northern Perspectives. http:www.carc.org/pubs/v25no4/4.htm.

O’Reilly, K., 1999. Impact benefit agreements: Tools for sustainable development? Canadian Arctic Resources Committee, Northern Perspectives, 25(4). http:www.carc.org/pubs/v25no4/1.htm.

O'Reilly, K. and Eacott. E., 1998. Aboriginal peoples and impact and benefit agreements: Report of a national workshop. Canadian Arctic Resource Committee, Northern Minerals Program Working Paper No. 7.

Reynolds, H., 1993. The mabo judgment - its implications. Oxfam Community Aid Abroad. http:www.caa.org.au/publications/reports/MABO/impl ications.html.

Wolford, W., 2005. Political ecology. http:www.unc.edu/depts/geog/people/faculty/wolford/. 